\title{
Electrical discharge phenomenon of electrode gaps in oil insulation
}

\author{
Jannus Maurits Nainggolan ${ }^{1 *}$, Iwa Ganiwa $\mathrm{MK}^{1}$, Chairul Hudaya ${ }^{1}$, and Amien Rahardjo ${ }^{1}$ \\ ${ }^{1}$ University of Indonesia, Department of Electrical Engineering, New Campus, Depok, 16424, Indonesia
}

\begin{abstract}
An electrical discharge is a phenomenon of ionization of an insulating material. Ionization can occur when the stress applied to the insulating material begins to close to the maximum value of stress can be restrained. In this study, a high voltage was given on a point-plane electrode that would produce ionization (discharge) on the gap of the electrode. The point-plane electrode was placed in an iron tank containing oil insulation. The distance of a gap between the electrodes varies from $2 \mathrm{~mm}$ to $4 \mathrm{~mm}$. Then, the signal from the occurrence of electrical discharge was capture using an acoustic emission (AE) sensor placed on the outside of the tank wall. The detected acoustic emission signal was amplified with a $40 \mathrm{~dB}$ amplifier, so the signal would be easier to analyze. At the other condition, a solid layer of insulation with a thickness of $4 \mathrm{~mm}$ would also be placed on the gap the electrode. The result of the signal analysis showed small differences in the intensity of the detected AE signal at all the distance of electrode gaps. The main frequency component of the detected AE signal at all electrode gaps was several hundred kilohertz.
\end{abstract}

\section{Introduction}

The need for electrical energy increases along with the growth of population and consumption lifestyle. It requires the state electric company to provide a better supply of electrical energy. Therefore, it needs the continuity and reliability of electric power system in order to meet the supply of electrical energy required by the society. A reliable electrical system is a system in which electrical equipment such as power cables, transformers, generators, can work and are not subject to interference. Good insulating systems are necessary to keep the equipment working properly.

A transformer is a very important asset in a distribution system and power transmission. Due to the very high cost and an important role of the uninterrupted power distribution system, large-size transformers cannot be easily replaced and can usually operate for decades. In the event of a failure, a power transformer can cost a great deal and need a considerable time interval for fabrication and replacement.

Generally, damage in an insulation system of electrical equipment such as transformer and generator takes place because of the high pressure of electric field. The electric field comes from an applied high voltage. A high electric field on insulation system can trigger a local discharge which is known as electrical discharge or partial discharge. Discharge is events of electrical sparks jump that occurs on one part of insulation as a result of the existence of high potential difference on isolation [1]. Occurrences of electrical discharge can also take place due to the poor quality of equipment construction, constant high pressure, contraction of insulation material, chemical factors, environmental factors, and heat effects that come up because of the increase of applied voltage.

When electrical or partial discharges occur, the energy generated is converted into different forms such as mechanical, electrical, heat and chemical energy. As a result, various techniques and types of sensors can be applied to detect the activity of partial discharge. On some electrical equipment using liquid/solid insulation, the effective method to measure the partial discharge is an acoustic emission method [2]. In this method, acoustic emission (AE) sensors are used to detect the elastic waves [3]. A discharge process will produce an energy that propagates in the form of elastic waves.

\section{Test Setup}

\subsection{Test preparation}

At this stage, a transformer box (tank) representing a real transformer [4] is made first from iron with a size of 30 $\mathrm{cm} \times 34 \mathrm{~cm} \times 36 \mathrm{~cm}$. The test electrodes are of stainless steel and in the form of sharp point-plane or needleplate. Needle electrode has a diameter of $9 \mathrm{~mm}$ and the tip is shaped $10 \mathrm{~mm}$. Plate electrode has a diameter of 80 $\mathrm{mm}$ and a thickness of $8 \mathrm{~mm}$. At the needle-plate electrode setup, the interval of gap (space) can be adjusted. In this test, the electrode gap distance is set at 2-4 mm. In the next setup, a thin layer of solid insulation with a certain thickness is placed between the needleplate electrodes.

\footnotetext{
* Corresponding author: mauritus24@gmail.com
} 


\subsection{Measurement of $A E$ signal and data processing}

Figure 3 shows the test setup for measurement of $\mathrm{AE}$ signals. An AE sensor is placed on the outer side of the metal tank. The needle electrode is connected to a high voltage. High voltage source was given and increased step by step until significant electrical discharge detected by $\mathrm{AE}$ sensor. The AE signal detected by the AE sensor with an operating frequency $100 \mathrm{kHz}-450 \mathrm{kHz}$. Then, the signal was amplified by a preamplifier of $40 \mathrm{~dB}$. The output of the amplifier was connected to a NI-USB Daq with a sampling frequency of $5 \mathrm{MHz}$ and recorded in a personal computer. To get the signal characteristics, these data will be analyzed by using a bandpass filter (BPF). A fast Fourier transform (FFT) also used to obtain the signal characteristics $[5,6,7]$.

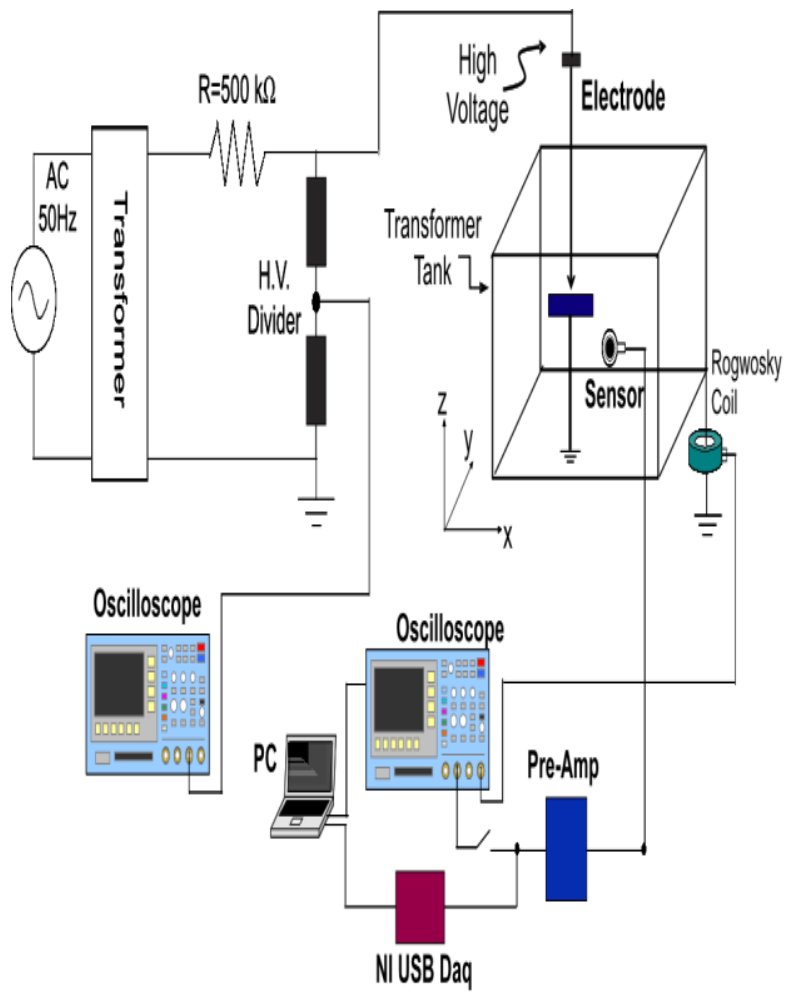

Fig. 1. Test setup for measurements of AE signal.

\section{Result and discussions}

The test was carried out at each electrode gap.

\subsection{Test on the electrode gap of $4 \mathrm{~mm}$}

At the electrode gap of $4 \mathrm{~mm}$, the detected AE signal was recorded first, then filtering conducted using a bandpass filter (BPF). The filtering of the signal used a BPF of $150-200 \mathrm{kHz}$ and BPF of $250-300 \mathrm{kHz}$, respectively shown in Figure 2 and Figure 3. In these figures are also shown the frequency spectra of the signal using FFT.

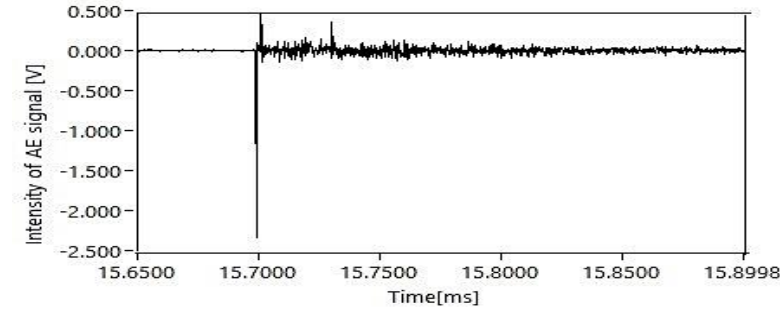

(a) AE signal detected by the sensor

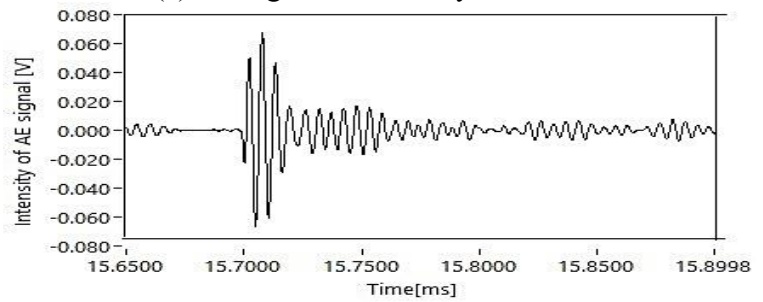

(b) A waveform obtained using BPF of $150 \mathrm{kHz}$ to $200 \mathrm{kHz}$

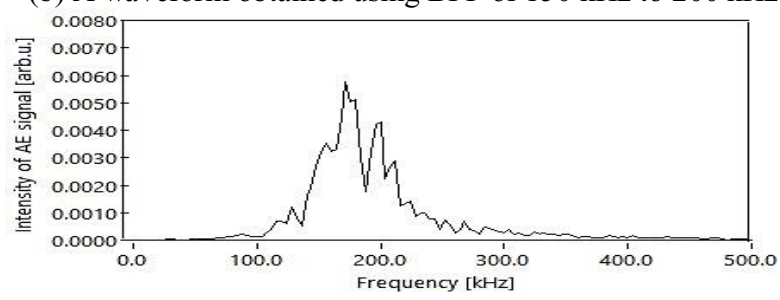

(c) Frequency spectra of (b)

Fig. 2. Detected AE signal, a waveform obtained using a BPF of $150 \mathrm{kHz}$ to $200 \mathrm{kHz}$ and frequency spectra for electrode gap of $4 \mathrm{~mm}$.

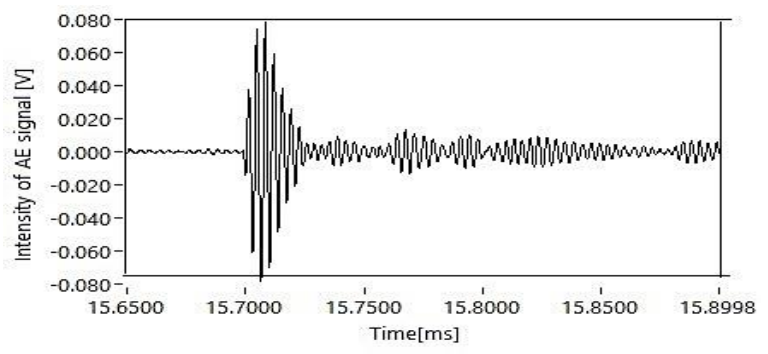

(a) The waveform of Fig. 2a obtained using BPF of $250 \mathrm{kHz}$ to $300 \mathrm{kHz}$

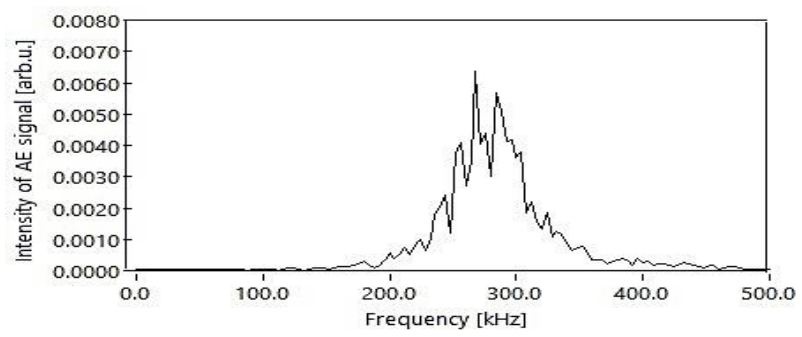

(b) Frequency spectra of (a)

Fig. 3. The waveform of detected AE signal obtained using a BPF of $250 \mathrm{kHz}$ to $300 \mathrm{kHz}$ and frequency spectra for electrode gap of $4 \mathrm{~mm}$.

From Figure 2 and Figure 3, it can be seen that the applying of a BPF of $250-300 \mathrm{kHz}$ gives better waveforms and greater signal intensity (see Figure 3 (a)) than a BPF of $150 \mathrm{kHz}$ to $200 \mathrm{kHz}$. This is due to a better signal to noise ratio (SNR) at filtering using 250$300 \mathrm{kHz}$. Figure 3 (b) also shows a larger amplitude of frequency spectra. In this condition, the intensity of the frequency spectra was around 0.007 (arbitrary unit). 


\subsection{Test on the electrode gap of $3 \mathrm{~mm}$}

At the electrode gap of $3 \mathrm{~mm}$, the detected AE signal was firstly recorded, then filtering conducted using a bandpass filter (BPF). The filtering of the signal using a BPF of $150-200 \mathrm{kHz}$ and BPF of $250-300 \mathrm{kHz}$, respectively shown in Figure 4 and Figure 5. In these figures are also shown the frequency spectra of the signal using FFT.

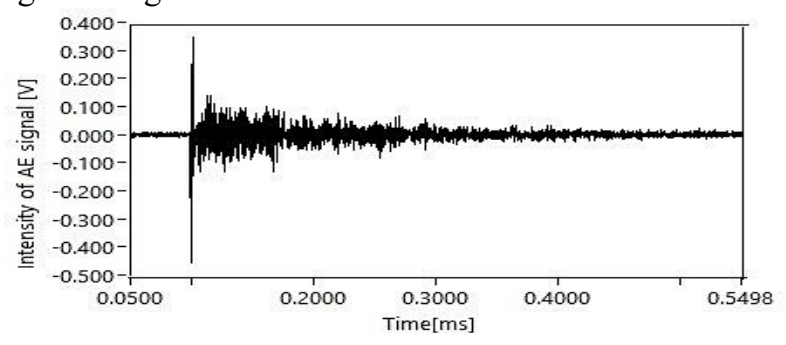

(a) AE signal detected by the sensor

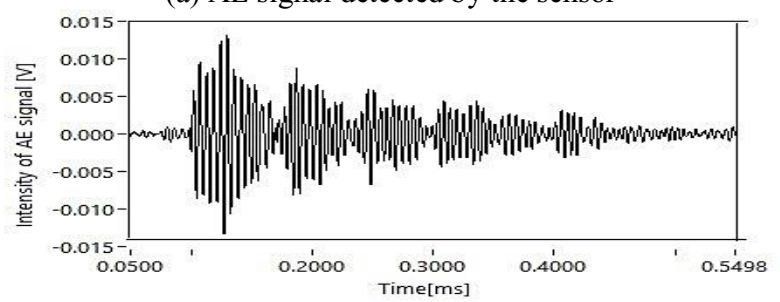

(b) A waveform obtained using BPF of $150 \mathrm{kHz}$ to $200 \mathrm{kHz}$

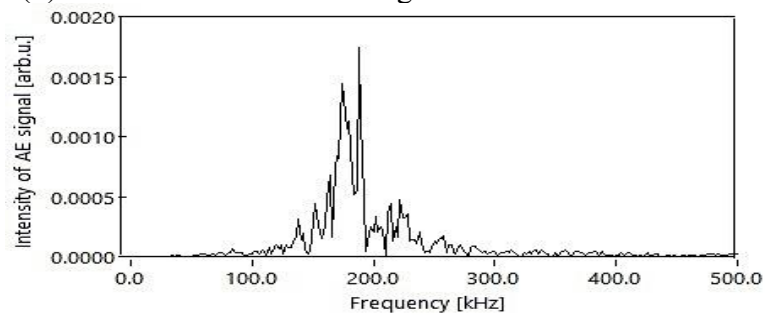

(b) Frequency spectra of (a)

Fig. 4. Detected AE signal, a waveform obtained using a BPF of $150 \mathrm{kHz}$ to $200 \mathrm{kHz}$ and frequency spectra for electrode gap of $3 \mathrm{~mm}$.

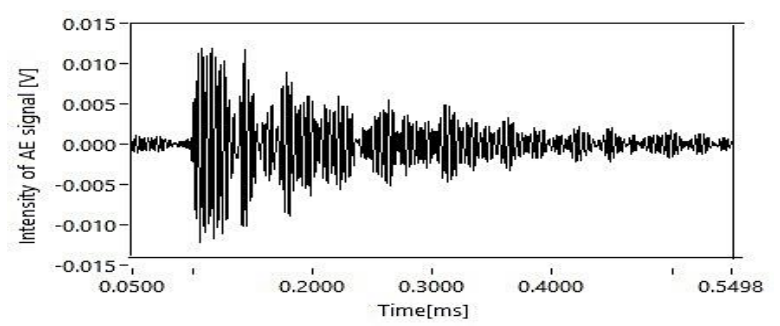

(a) The waveform of Fig. 4a obtained using BPF of $250 \mathrm{kHz}$ to $300 \mathrm{kHz}$

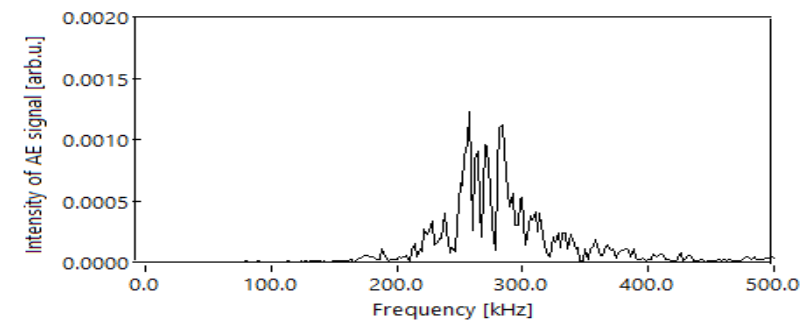

(b) Frequency spectra of (a)

Fig. 5. The waveform of detected AE signal obtained using a $\mathrm{BPF}$ of $250 \mathrm{kHz}$ to $300 \mathrm{kHz}$ and frequency spectra for electrode gap of $3 \mathrm{~mm}$.
From Figure 4 and Figure 5, it can be seen that the applying of a BPF of $150-200 \mathrm{kHz}$ contributes better waveforms and greater signal intensity (see figure 4 (a)) than a BPF of $250 \mathrm{kHz}$ to $300 \mathrm{kHz}$. This is due to a better signal to noise ratio (SNR) at filtering using 150$200 \mathrm{kHz}$. Figure 4 (b) also shows a larger amplitude of frequency spectra.

\subsection{Test on the electrode gap of $2 \mathrm{~mm}$}

At the electrode gap of $2 \mathrm{~mm}$, the filtering of detected AE signal using a BPF of $150-200 \mathrm{kHz}$ and BPF of 250$300 \mathrm{kHz}$, respectively shown in Fig. 6 and Fig. 7. These figures also showed the frequency spectra of the signal using FFT.

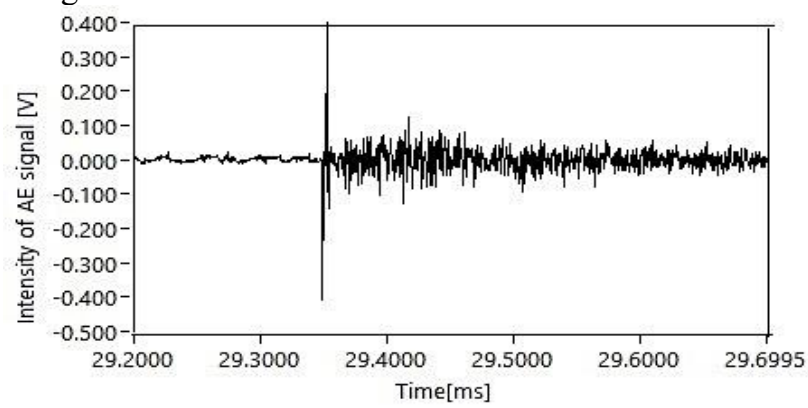

(a) AE signal detected by the sensor

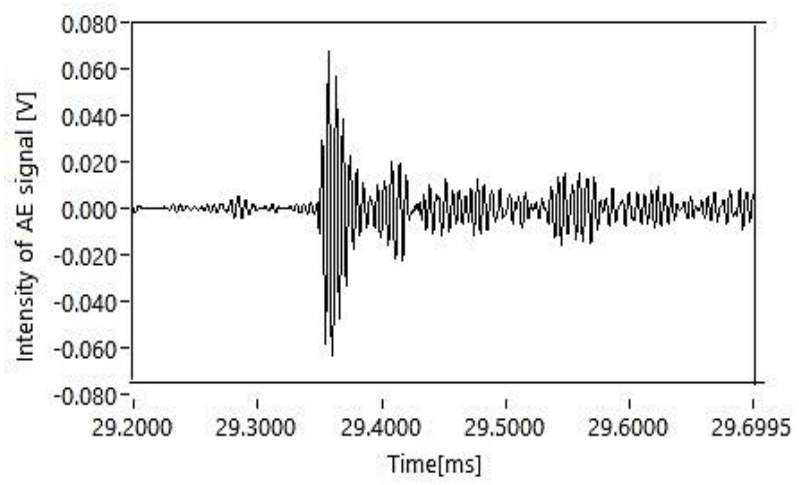

(b) A waveform obtained using BPF of $150 \mathrm{kHz}$ to $200 \mathrm{kHz}$

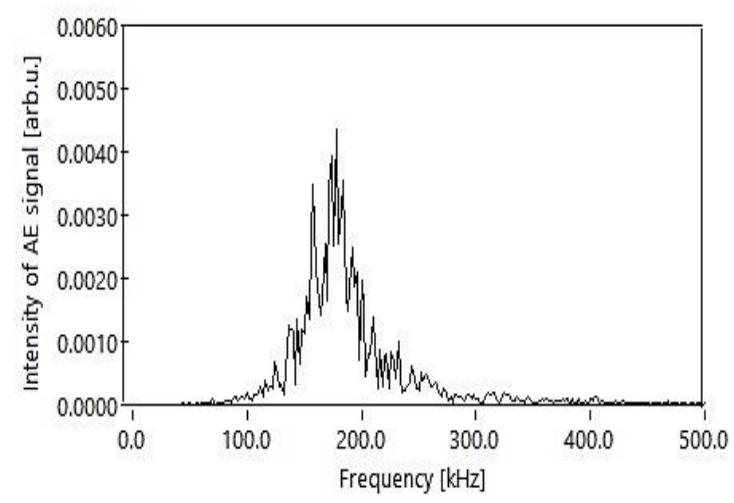

(c) Frequency spectra of (b)

Fig. 6. Detected AE signal, a waveform obtained using a BPF of $150 \mathrm{kHz}$ to $200 \mathrm{kHz}$, and frequency spectra for electrode gap of $2 \mathrm{~mm}$. 

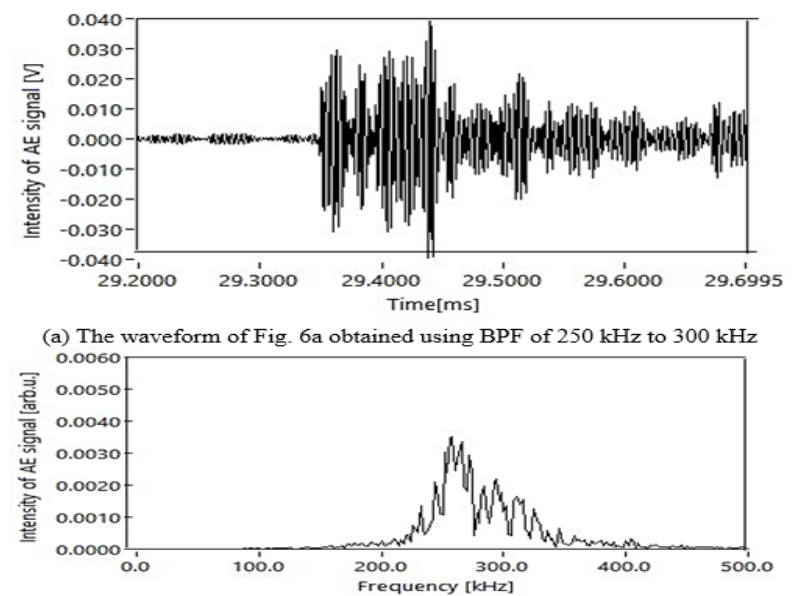

(b) Frequency spectra of (a)

Fig. 7. The waveform of detected AE signal obtained using a BPF of $250 \mathrm{kHz}$ to $300 \mathrm{kHz}$ and frequency spectra for electrode gap of $2 \mathrm{~mm}$.

From Figure 6 and Figure 7, it can be seen also that the operating of a BPF of $150-200 \mathrm{kHz}$ gives better waveforms and greater signal intensity (see Figure 6 (a)) than a BPF of $250 \mathrm{kHz}$ to $300 \mathrm{kHz}$. This is due to a better signal to noise ratio (SNR) at filtering using 150$200 \mathrm{kHz}$.

\subsection{Test on a solid insulation layer of $0.4 \mathrm{~mm}$}

At the electrode gap with a solid insulation layer of 0.4 $\mathrm{mm}$, the detected AE signal was recorded in the event of discharge and failure (breakdown). The filtering of the detected AE signal using a BPF of $150-200 \mathrm{kHz}$ shown in Figure 8. In this figures is also shown the frequency spectra of the signal using FFT.

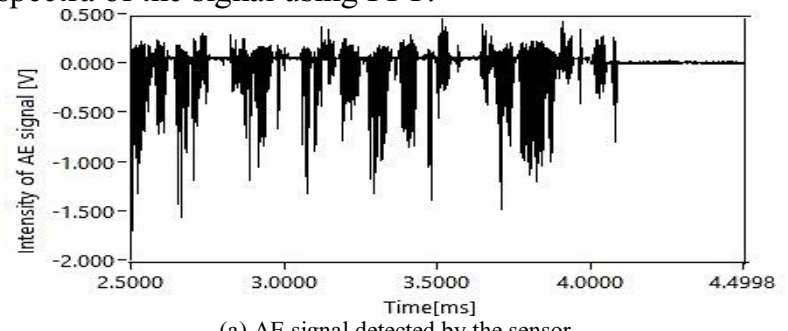

(a) AE signal detected by the sensor
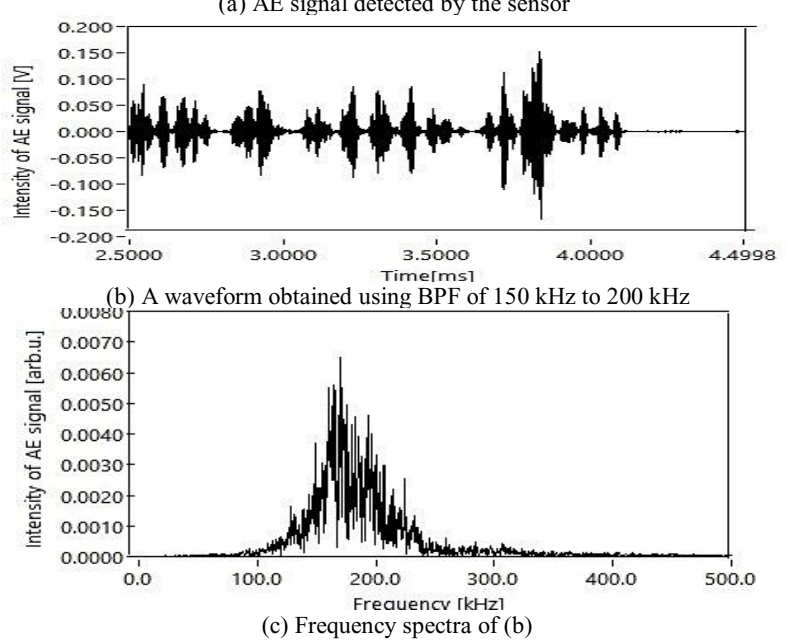

Fig. 8. Detected AE signal, a waveform obtained using a BPF of $150 \mathrm{kHz}$ to $200 \mathrm{kHz}$ and frequency spectra for a solid insulation layer of $0.4 \mathrm{~mm}$
From Figure 8 (a), it is shown that there is a very intense electrical (partial) discharge phenomenon, followed by a sudden failure process. The failure process can be indicated by an impulse at the end of the signal (see Figure 8 (b). Failure occurs because solid insulation cannot restrain the stress of a given voltage. This may be due to a fairly thin insulation layer thickness.

\section{Conclusions}

In this study, the pattern and the intensity of electrical or partial discharges at all distances of electrode gaps showed small differences when filtered using a BPF of $150 \mathrm{kHz}$ to $200 \mathrm{kHz}$ and BPF of $250 \mathrm{kHz}$ to $300 \mathrm{KHz}$. This may be due to a fairly small distance of electrode gaps. So, the value of the dominant frequency of the electrical discharge was several hundred kilohertz. A more intense electrical (partial) discharge pattern occurs in the test with solid insulation layer located on the electrode gap. In this condition, small insulation surface resistance can cause this pattern, and eventually breaks due to a quite thin insulation thickness.

\section{References}

1. P. Kundu, N.N. Kishore, A.K. Sinha, N.A. Algeelani, M.A. M Piah, N. Bashir, Elsevier-Applied Acoustics, 73, 395 (2012)

2. M. Harbaji, K. Shaban, A. El-Hag, IEEE Trans. Dielectr. Electr. Insul. 22, 1674-1683 (2015)

3. C.J. Hellier, Handbook of Nondestructive Evaluation, Chapter 10 (McGraw-Hill Companies, 2003)

4. C. Boya, M. Ruiz-Liata, J. Posada, J.A. GarciaSouto, IEEE Trans. Dielectr. Electr. Insul. 22, 16631673 (2015)

5. J.M. Nainggolan, T. Nakashima, T. Sakoda, M. Otsubo, S. Kurihara, T. Yarimitsu, S. Nagasato, 2010 Annual Report Conference on Electrical Insulation and Dielectric Phenomena, 442-445 (2010)

6. J.M, Nainggolan, I. Garniwa MK, A. Raharjo, IOP Conf. Ser.: Mater. Sci. Eng. 190 (2017)

7. J. Rubio-Serano, Boya, M.V. Rojas-Moreno, J. Posada, J.M. Martinez-Tarifa, G. Robies, IEEE Trans. Dielectr. Electr. Insul. 19, 1569-1578 (2012) 